\title{
Beberapa Sifat Ideal Bersih-N
}

\author{
Uha Isnaini dan Indah Emilia Wijayanti \\ Jurusan Matematika FMIPA UGM, Yogyakarta, Sekip Utara, Bulaksumur 21, Yogyakarta 55281, \\ Indonesia
}

Korespondensi; Uha Isnaini: isnainiuha@ugm.ac.id, Indah Emilia Wijayanti: ind_wijayanti@ugm.ac.id

\begin{abstract}
Abstrak
Diketahui $R$ ring dengan elemen satuan dan I ideal di R. Dalam tulisan ini akan dikaji ideal bersih-n yang merupakan perumuman ideal bersih dan belum pernah dikaji oleh peneliti sebelumnya. Ideal I disebut ideal bersih-n jika untuk setiap elemen ideal I dapat dinyatakan dalam jumlahan suatu idempoten di $\mathbf{R}$ dengan $\mathbf{n}$ buah unit di $\mathbf{R}$. Dalam tulisan dibicarakan beberapa sifat dari ideal bersih-n yang meliputi: definisi dan contoh ideal bersih-n, hubungan antara ideal bersih-n dengan ideal peralihan, sifat ideal bersih-n jika dikaitkan dengan isomorfisma, Kartesian produk dari ideal bersih-n, serta pembentukan matriks atas ideal bersih-n.
\end{abstract}

Kata Kunci: Ring bersih; ideal bersih; ideal bersih-n; matriks atas ideal bersih - $n$

\begin{abstract}
Unknown $\mathbf{R}$ ring with unit element and I an ideal in $R$. In this paper will be assessed ideal clean-n which is an ideal generalization clean and have not been reviewed by previous researchers. Ideal I called ideal clean-n if for every element ideal I can be expressed in a sum of an idempotent in $\mathbf{R}$ with $\mathbf{n}$ unit in $\mathbf{R}$. In the paper discussed some properties of an ideal clean-n which includes: definition and examples of clean base-n, the relationship between ideal clean- $n$ to the ideal transition, ideal properties net-n if associated with isomorphism, Cartesian product of the ideal clean-n, as well as an ideal matrix formation on clean-n.
\end{abstract}

Keywords: Ring clean; ideal net; ideal clean-n; the matrix on net ideal - $\mathrm{n}$

\section{Pendahuluan}

Lapangan merupakan ring yang mempunyai sifat-sifat khusus. Sebarang elemen lapangan $F$ dapat dinyatakan sebagai jumlahan suatu elemen idempoten dengan suatu elemen unit. Tetapi untuk sebarang ring $R$ sifat tersebut belum tentu berlaku. Suatu elemen $x$ dalam ring $R$ yang dapat dinyatakan sebagai jumlahan idempoten dengan unit disebut elemen bersih. Secara umum tidak semua ring setiap elemennya merupakan elemen bersih. Ring yang setiap elemennya merupakan elemen bersih disebut ring bersih.

Dasar teori mengenai ring dengan elemen satuan diambil dari buku Fraleigh (1999). Kemudian untuk dasar teori tentang modul, hasil kali langsung suatu modul dan homomorfisma modul digunakan buku Adkins dan Weintraub (1992). Untuk dasar teori tentang sifat-sifat modul, bimodul dan hasil kali tensor digunakan buku Anderson dan Fuller (1992).

Wang dan Chen (2006) memperkenalkan ring bersih-2 yang merupakan perumuman ring bersih. Setelah itu Khaksari dan Moghimi (2009) membahas ring bersih $-n$ yang merupakan perumuman ring bersih-2. Ring bersih- $n$ adalah ring yang setiap elemennya dapat dinyatakan dalam jumlahan idempoten dan $n$ buah unit.

Ideal suatu ring bersih belum tentu merupakan ring bersih juga, karena tidak ada jaminan idempoten dan unit yang menjadi komponen masing-masing elemennya berada di dalam ideal tersebut. Oleh karena itu didefinisikan ideal bersih, yaitu ideal yang setiap elemennya dapat dinyatakan dalam jumlahan idempoten dan unit di $R$.

Untuk definisi dan pembahasan sifat-sifat ideal bersih dikemukakan oleh Chen dan Chen (2002). Pada paper tersebut didefinisikan ideal bersih merupakan ideal yang setiap elemennya dapat dinyatakan 
dalam jumlahan idempoten di $R$ dan unit di $R$. Selanjutnya diperkenalkan ideal bersih $-n$ yang merupakan perumuman ideal bersih dan terinspirasi dari ring bersih $-n$. Didefinisikan ideal bersih- $n$ beserta sifat-sifatnya belum pernah dibahas oleh penulis-penulis sebelumnya.

\section{Hasil dan Pembahasan}

Pada keseluruhan paper, yang dimaksud dengan ring adalah ring dengan elemen satuan. Himpunan $I$ I $(R)$ merupakan himpunan elemen identitas di $R$, sedangkan $U(R)$ merupakan himpunan elemen unit di $R$. Sebagai dasar untuk pendefinisian ideal bersih $-n$, pertama-tama diberikan definisi ideal bersih:

Definisi 1. Ideal I disebut ideal bersih jika untuk setiap $x \in I, x=e+u$ untuk suatu $e \in$ I. $(R)$ dan $u \in U(R)$.

Dengan kata lain, ideal bersih merupakan ideal yang setiap elemennya merupakan elemen bersih. Dari definisi tersebut, jelas bahwa setiap ideal dari ring bersih merupakan ideal bersih. Namun ada ring yang bukan merupakan ring bersih tetapi memuat ideal bersih (Chen dan Chen, 2002).

Selanjutnya diberikan definisi ring bersih $-n$ sebagai berikut.

Definisi 2. Ring $R$ disebut ring bersih-n jika untuk setiap $x \in R, x=e+u_{1}+u_{2}+\cdots+u_{n}$ untuk suatu $e \in I,(R)$ dan $u_{i} \in U(R), i=1,2, \ldots, n$.

Selanjutnya setiap elemen di ring yang dapat dinyatakan sebagai jumlahan idempoten dengan $n$ buah unit disebut dengan elemen bersih $-n$. Dengan kata lain ring bersih $-n$ merupakan ring yang setiap elemennya merupakan elemen bersih $-n$. Dapat dilihat, ring bersih dapat dipandang sebagai ring bersih-1. Jadi ring bersih $n$ merupakan perumuman dari ring bersih. Dari fakta definisi ideal bersih dan ring bersih $-n$ tersebut, didefinisikan ideal bersih $-n$ sebagai berikut.

Definisi 3. Ideal I disebut ideal bersih-n jika untuk setiap $x \in I, x=e+u_{1}+u_{2}+\cdots+u_{n}$ untuk suatu $e \in I,(R)$ dan $u_{i} \in U(R), i=1,2, \ldots, n$.

Dari definisi tersebut, jelas bahwa setiap ideal dari ring bersih $-n$ merupakan ideal bersih $-n$. Namun ada ring yang bukan merupakan ring bersih $-n$ memuat ideal bersih $-n$. Diberikan ring $R_{\mathbf{1}}$ yang merupakan ring bersih $-n$, dan $R_{2}$ yang bukan merupakan ring bersih $-n$. Dibentuk ring $R=R_{1}$ $\oplus R_{2}$ dengan operasi penjumlahan dan perkalian per komponen. Jelas bahwa $R$ bukan merupakan ring bersih $-n$. Kemudian dibentuk ideal $l=R_{1} \oplus 0$. Diambil sebarang $(x, 0) \in l$, karena $R$ ring bersih- $n$ maka ada suatu idempoten $e_{1}$ dan $\mathrm{n}$ buah unit $u_{1}, u_{2}, \ldots, u_{n}$ sedemikian hingga $x=e_{1}+u_{1}+u_{2}+\cdots+u_{n}$. Kemudian $(x, 0)$ dapat dinyatakan sebagai $(x, 0)=\left(e_{1}, 1\right)+\left(u_{1},-1\right)+$ $\cdots+\left(u_{n-1}, 1\right)+\left(u_{n},-1\right)$ untuk $\mathrm{n}$ ganjil, dan untuk $\mathrm{n}$ genap didapat $(x, 0)=\left(e_{1}, 0\right)+\left(u_{1}, 1\right)+$ $\left(u_{2},-1\right) \ldots+\left(u_{n-1}, 1\right)+\left(u_{n},-1\right)$. Jelas bahwa $\left(e_{1}, 0\right),\left(e_{1}, 1\right) \in \operatorname{ld}(R)$ dan $\left(u_{i}, 1\right),\left(u_{i},-1\right) \in$ $U(R)$, untuk setiap $i=1,2, \ldots, n$. Jadi $l$ merupakan ideal bersih $-n$.

Lemma 4. Jika $x$ elemen bersih maka $x$ merupakan elemen bersih-n, untuk setiap bilangan asli $n$.

Bukti. Bukti menggunakan induksi matematika. Untuk $n=1$ jelas berlaku, karena definisi elemen bersih dan elemen bersih-1 sama. Kemudian diasumsikan benar untuk $n=k$, $x$, didapat dinyatakan $x=e+u_{1}+\cdots+u_{k}$ untuk suatu $e \in I_{1}(R)$ dan $u_{1}, \ldots, u_{k} \in U(R)$. Kemudian $x$ dapat dinyatakan dalam $x=(1-e)+(2 e-1)+u_{1}+\cdots+u_{k}$ dengan $1-e \in I_{1}(R)$ dan $2 e-1 \in$ $U(R)$. 
Dari Lemma 4, diperoleh akibat sebagai berikut.

Akibat 5. Jika 1 ideal bersih maka 1 ideal bersih-n, untuk setiap bilangan asli $n$.

Bukti. Karena setiap elemen bersih merupakan elemen bersih- $n$, didapat $I$ merupakan ideal bersihn.

Konvers dari Akibat 5 belum tentu berlaku. Dengan kata lain jika untuk suatu bilangan asli $n \neq$ $1, I$ merupakan ideal bersih $-n$, maka $I$ belum tentu ideal bersih. Diberikan contoh penyangkal sebagai berikut.

Contoh 6. Diberikan ring matriks $M_{2}(\mathbb{Z})$. Diperhatikan bahwa $M_{2}(2 \mathbb{Z})$ ideal $M_{2}(\mathbb{Z})$ tetapi bukan ideal bersih karena ada $\left[\begin{array}{ll}4 & 0 \\ 0 & 0\end{array}\right] \in M_{2}(2 \mathbb{Z})$ bukan elemen bersih. Andaikan $\left[\begin{array}{ll}4 & 0 \\ 0 & 0\end{array}\right]$ merupakan elemen bersih, maka $\left[\begin{array}{ll}4 & 0 \\ 0 & 0\end{array}\right]=\left[\begin{array}{ll}-a & -b \\ -c & -d\end{array}\right]+E$ dengan $U=\left[\begin{array}{ll}-a & -b \\ -c & -d\end{array}\right] \in G_{2}(\mathbb{Z})$ dan $E \in I_{1}(\mathbb{Z})$. Karena $U$ unit, didapat dan $\operatorname{det}(U)=1$ atau -1 . Diperhatikan $(\operatorname{det}(E))^{2}=\operatorname{det}(E) \operatorname{det}(E)=\operatorname{det}\left(E^{2}\right)=$ $\operatorname{det}(E)$, jadid $(E)=0$ atau $1 . \quad$ Didapat $\operatorname{det}(E)=\operatorname{det}\left(\left[\begin{array}{cc}4+a & b \\ c & d\end{array}\right]\right)=4 d+a-b=4 d+$ $\operatorname{det}(U)=0$ atau 1. Persamaan tersebut memiliki solusi jika $d(U)=1$ dan $d(E)=0$, didapat $d=0$. Kemudiand $(E)=\operatorname{det}\left(\left[\begin{array}{cc}4+a & b \\ c & 0\end{array}\right]\right)=-\mathrm{bc}=0$ didapat $b=0$ atau $c=0$. Jadi $d(U)=$ 0 , kontradiksi dengan $d(U)=1$ atau -1 . Jadi $\left[\begin{array}{ll}4 & 0 \\ 0 & 0\end{array}\right]$ bukan merupakan elemen bersih.

Kemudian ditunjukkan bahwa $M_{2}(2 \mathbb{Z})$ merupakan ideal bersih-2. Diambil sebarang $X=\left[\begin{array}{ll}a & b \\ c & d\end{array}\right] \in$ $M_{2}(2 \mathbb{Z})$ didapat

$$
X=P^{-1}\left[\begin{array}{ll}
1 & 1 \\
1 & 0
\end{array}\right] Q^{-1}+P^{-1}\left[\begin{array}{cc}
0 & -1 \\
-1 & v
\end{array}\right] Q^{-1}+E
$$

dengan $v=a^{2}+a-c-c-2 a+2 c-b+d$

$$
P=\left[\begin{array}{cc}
1 & 0 \\
a-c-1 & 1
\end{array}\right] \quad Q=\left[\begin{array}{cc}
1 & 2-a-b \\
0 & 1
\end{array}\right] \quad E=\left[\begin{array}{cc}
a-1 & 2-a \\
a-1 & 2-a
\end{array}\right] \text {. }
$$

Jadi $M_{2}(2 \mathbb{Z})$ merupakan ideal bersih-2.

Selanjutnya diberikan lemma yang menyatakan hubungan ideal bersih $-n$ dengan petanya.

Lemma 7. Diketahui ring $R$ dan $R^{\prime}, I$ ideal $R$ dan pemetaan $f: R \rightarrow R^{\prime}$ merupakan epimorfisma. Jika 1 ideal bersih-n di $R$ maka $f(I)$ dengan $f(I)=\{f(i) \mid i \in I\}$ merupakan ideal bersih-n di $R^{\prime}$.

Bukti. Menurut teori ring dan karena $f$ epimorfisma, $f(I)$ merupakan ideal $R^{\prime}$. Diambil sebarang $f(x) \in f(I)$. Karena $l$ ideal bersih-n maka $x=e+u_{1}+\cdots+u_{n}$ untuk suatu $e \in I_{1}(R)$ dan $u_{1}, \ldots, u_{n} \in U(R)$. Kemudian didapat $f(x)=f\left(e+u_{1}+u_{2}+\cdots+u_{n}\right)=f(e)+f\left(u_{1}\right)+f\left(u_{2}\right)+$ $\cdots+f\left(u_{n}\right)$ dengan $f(e) \in I_{1}\left(R^{\prime}\right)$ dan $f\left(u_{1}\right), \ldots, f\left(u_{n}\right) \in U(R)$. Jadi $f(I)$ ideal bersih $-n$ di $R^{\prime}$.

Selanjutnya diberikan lemma yang menyajikan sifat ideal bersih $-n$ pada pergandaan Kartesius.

Lemma 8. Untuk setiap bilangan asli $i, l_{i}$ ideal bersih-n di $R_{i}$ jika dan hanya jika $\prod I_{i}$ ideal bersih-n di $\prod R_{i}$. 
Bukti. $(\Rightarrow)$ Diambil sebarang $\bar{x}=\left(x_{1}, x_{2}, \ldots\right) \in \prod l$. Karena untuk setiap bilangan asli $i, l_{i}$ ideal bersih-n didapat $x_{i}=e_{i}+u_{i 1}+u_{i 2}+\cdots+u_{n}$ untuk suatu $e_{i} \in I_{1}\left(R_{i}\right)$ dan $u_{i 1}, u_{i 2}, \ldots, u_{i 1} \in$ $U\left(R_{i}\right)$. Diperoleh $\bar{x}$ dapat dinyatakan dalam $\bar{x}=\left(e_{1}, e_{2}, \ldots\right)+\left(u_{1}, u_{2}, \ldots\right)+\cdots+\left(u_{1 n}, u_{2 n}, \ldots\right)$, dengan $\left(e_{1}, e_{2}, \ldots\right) \in I_{1}\left(\prod R\right)$ dan $\left(u_{1 k}, u_{2 k}, \ldots\right) \in U\left(\prod R\right)$ untuk setiap bilangan asli $k$. Jadi $\prod$ lideal bersih-n $\operatorname{di} \prod R$.

$(\Leftarrow)$ Diambil sebarang $x \in l_{i}$, didapat $\underbrace{(0,0, \ldots, x, \ldots)}_{s} \in \prod l$. Karena $\prod l$ ideal bersih-n, maka $\underbrace{(0,0, \ldots, x, \ldots)}_{s}=\underbrace{(*, *, \ldots, e, \ldots)}_{s-i}+\sum_{k=1}^{n} \underbrace{\left(*, *, \ldots, u_{k}, \ldots\right)}_{s}$ untuk suatu $\underbrace{(*, *, \ldots, e, \ldots)}_{s-i} \in I_{k-i}\left(\prod R\right)$ dan $\underbrace{\left(*, *, \ldots, u_{k}, \ldots\right)}_{s} \in U\left(\prod R\right), k=1,2, \ldots, n$. Menggunakan sifat elemen idempotent dan unit didapate $\in$ I. $\left(R_{i}\right)$ dan $u_{1}, u_{2}, \ldots, u_{n} \in U\left(R_{i}\right)$. Jadi $x=e+u_{1}+u_{2}+\cdots+u_{n}$, sehingga untuk setiap $i$ didapat $I_{i}$ ideal bersih $-n$ di $R_{i}$.

Telah dikenal bahwa $l$ ideal $R$ disebut ideal peralihan jika untuk setiap $x \in l$ terdapat elemen idempoten $e$ sedemikan hingga $e-x \in R\left(x-x^{2}\right)$. Berikut diberikan hubungan antara ideal peralihan dengan ideal bersih-n.

Teorema 9. Diketahui ring $R, I$ ideal $R$ dan setiap elemen idempoten $R$ sentral. Jika $I$ ideal peralihan maka I ideal bersih-n untuk suatu bilangan asli $n$.

Bukti. Menggunakan [3, Teorema 1.3] didapat $\mathbf{l}$ merupakan ideal bersih. Sehingga didapat $\mathbf{l}$ merupakan ideal bersih $-n$. $\square$

Konvers dari teorema tersebut belum tentu berlaku. Menggunakan Contoh 6 , dapat ditunjukkan $I$ bukan merupakan ideal peralihan. Diambil $X=\left[\begin{array}{ll}4 & 0 \\ 0 & 0\end{array}\right] \in M_{2}(2 \mathbb{Z})$. Diambil sebarang $E=\left[\begin{array}{ll}a & b \\ C & d\end{array}\right] \in$ $I_{1}\left(M_{2}(\mathbb{Z})\right)$ dan $R=\left[\begin{array}{ll}p & q \\ r & s\end{array}\right] \in M_{2}(\mathbb{Z})$. Pertama-tama akan ditunjukkan $E-X \neq R\left(X-X^{2}\right)$.

Perhatikan bahwa

$$
\begin{gathered}
E-X=\left[\begin{array}{cc}
a-4 & b \\
c & d
\end{array}\right] \text { dan } \\
R\left(X-X^{2}\right)=\left[\begin{array}{ll}
p & q \\
r & s
\end{array}\right]\left(\left[\begin{array}{ll}
4 & 0 \\
0 & 0
\end{array}\right]-\left[\begin{array}{cc}
16 & 0 \\
0 & 0
\end{array}\right]\right)=\left[\begin{array}{ll}
p & q \\
r & s
\end{array}\right]\left[\begin{array}{cc}
-12 & 0 \\
0 & 0
\end{array}\right]=\left[\begin{array}{cc}
-12 p & 0 \\
-12 r & 0
\end{array}\right] .
\end{gathered}
$$

Didapat $b=0$ dan $d=0$. Karena $E^{2}=\left[\begin{array}{ll}a & 0 \\ c & 0\end{array}\right]^{2}=\left[\begin{array}{ll}a & 0 \\ c & 0\end{array}\right]\left[\begin{array}{ll}a & 0 \\ c & 0\end{array}\right]=\left[\begin{array}{ll}a^{2} & 0 \\ c & 0\end{array}\right]=\left[\begin{array}{ll}a & 0 \\ c & 0\end{array}\right]=E$, didapat $a=1$ atau $a=0$. Untuk $a=1,1-4=-3=-12 p$ dan untuk $a=0,0-4=-4=-12 p$. Karena $p$ bilangan bulat, persamaan tersebut tidak mempunyai solusi. Dengan kata lain $E-X \neq$ $R\left(X-X^{2}\right)$. Jadi untuk setiap $E \in I_{1}\left(M_{2}(\mathbb{Z})\right), E-X \notin R\left(X-X^{2}\right)$. Dengan kata lain $l$ bukan merupakan ideal peralihan.

Teorema 10. Jika / ideal bersih-n di $R$, maka $M_{k}(I)$ merupakan ideal bersih-n di $M_{k}(R)$.

Bukti. Diambil sebarang $\left[\begin{array}{cccc}a_{1} & a_{1} & \ldots & a_{1 k} \\ a_{2} & a_{2} & \ldots & a_{2 k} \\ \vdots & \vdots & \ddots & \vdots \\ a_{k 1} & a_{k 2} & \ldots & a_{k}\end{array}\right] \in M_{k}(R)$. Karena $l$ ideal bersih $n$, setiap entrinya dapat dinyatakan dalam jumlahan idempoten dan $n$ buah unit. Didapat 


$$
\begin{aligned}
& {\left[\begin{array}{cccc}
a_{1} & a_{1} & \ldots & a_{1 k} \\
a_{2} & a_{2} & \ldots & a_{2 k} \\
\vdots & \vdots & \ddots & \vdots \\
a_{k 1} & a_{k 2} & \ldots & a_{k}
\end{array}\right]=\left[\begin{array}{cccc}
e_{1} & 0 & \ldots & 0 \\
0 & e_{2} & \ldots & 0 \\
\vdots & \vdots & \ddots & \vdots \\
0 & 0 & \ldots & e_{k}
\end{array}\right]+\left[\begin{array}{cccc}
u_{1}^{1} & 0 & \ldots & 0 \\
a_{2} & u_{2}^{1} & \ldots & 0 \\
\vdots & \vdots & \ddots & \vdots \\
a_{k 1} & a_{k 2} & \ldots & u_{k}^{1}
\end{array}\right]+} \\
& {\left[\begin{array}{cccc}
u_{1}^{2} & a_{1} & \ldots & a_{1 k} \\
0 & u_{2}^{2} & \ldots & a_{2 k} \\
\vdots & \vdots & \ddots & \vdots \\
0 & 0 & \ldots & u_{k}^{2}
\end{array}\right]+\left[\begin{array}{cccc}
u_{1}^{3} & 0 & \ldots & 0 \\
0 & u_{2}^{3} & \ldots & 0 \\
\vdots & \vdots & \ddots & \vdots \\
0 & 0 & \ldots & u_{k}^{3}
\end{array}\right]+\cdots+\left[\begin{array}{cccc}
u_{1}^{n} & 0 & \ldots & 0 \\
0 & u_{2}^{n} & \ldots & 0 \\
\vdots & \vdots & \ddots & \vdots \\
0 & 0 & \ldots & u_{k}^{n}
\end{array}\right] .}
\end{aligned}
$$

Jadi $M_{k}(I)$ merupakan ideal bersih- $n$ di $M_{k}(R)$.

Konvers dari Teorema tersebut belum tentu berlaku. Dari Contoh 6, diperoleh $M_{2}(2 \mathbb{Z})$ merupakan ideal bersih-2 di $M_{2}(\mathbb{Z})$. Namun $2 \mathbb{Z}$ bukan merupakan ideal bersih-2 di $\mathbb{Z}$ karena $4 \in \mathbb{Z}$ bukan merupakan elemen bersih-2.

Untuk mempersingkat penulisan, matriks segitiga bawah berukuran $k \times k$ atas $R$ disimbolkan dengan $M_{k}(\lfloor R\rfloor)$. Berikut diberikan hubungan antara $M_{k}(\lfloor R\rfloor)$ dengan $M_{k}(\lfloor I\rfloor)$.

Lemma 11. Ideal $l$ merupakan ideal bersih-n di $R$ jika dan hanya jika $M_{k}(\lfloor I])$ ideal bersih- $n$ di $M_{k}(\lfloor R\rfloor)$.

Bukti. $(\Rightarrow)$ Untuk $k=1$ jelas. Diasumsikan benar untuk $k-1,(k>1)$, akan ditunjukkan benar untuk $k$. Diambil sebarang $A$, maka $A$ dapat dinyatakan dengan $A=\left[\begin{array}{ll}a & 0 \\ r & B\end{array}\right]$.Karena $a \in I$ didapat $a=e+u_{1}+\cdots+u_{n}$.Karena $B$ berukuran k 1 didapat $B=F+V_{1}+\cdots+V_{n}$.

Dibentuk

$$
E=\left[\begin{array}{ll}
e & 0 \\
0 & F
\end{array}\right] \text { dan } U_{1}=\left[\begin{array}{cc}
u_{1} & 0 \\
r & V_{1}
\end{array}\right], U_{n}=\left[\begin{array}{cc}
u_{n} & 0 \\
r & V_{n}
\end{array}\right]
$$

sehingga $A=e+U_{1}+\cdots+U_{n}$. Jadi $M_{k}(\lfloor I])$ ideal bersih-n di $M_{k}(\lfloor R\rfloor)$.

$(\Leftarrow)$ Diambil sebarang $x \in I$, didapat $\left[\begin{array}{cccc}x & 0 & \ldots & 0 \\ 0 & 0 & \ldots & 0 \\ \vdots & \vdots & \ddots & \vdots \\ 0 & 0 & \ldots & 0\end{array}\right] \in M_{k}(\lfloor I])$. Didapat ada idempotent $\left[\begin{array}{cccc}e_{1} & 0 & \ldots & 0 \\ * & e_{2} & \ldots & 0 \\ \vdots & \vdots & \ddots & \vdots \\ * & * & \ldots & e_{k}\end{array}\right]$ dan $\mathrm{n}$ buah unit $\left[\begin{array}{cccc}u_{1 i} & 0 & \ldots & 0 \\ * & u_{2 i} & \ldots & 0 \\ \vdots & \vdots & \ddots & \vdots \\ * & * & \ldots & u_{k}\end{array}\right]$ dengan $i=1,2, \ldots, n$.Matriks awal dapat dinyatakan dengan

$\left[\begin{array}{cccc}x & 0 & \ldots & 0 \\ 0 & 0 & \ldots & 0 \\ \vdots & \vdots & \ddots & \vdots \\ 0 & 0 & \ldots & 0\end{array}\right]=\left[\begin{array}{cccc}e_{1} & 0 & \ldots & 0 \\ * & e_{2} & \ldots & 0 \\ \vdots & \vdots & \ddots & \vdots \\ * & * & \ldots & e_{k}\end{array}\right]+\sum_{i=1}^{n}\left[\begin{array}{cccc}u_{1 i} & 0 & \ldots & 0 \\ * & u_{2 i} & \ldots & 0 \\ \vdots & \vdots & \ddots & \vdots \\ * & * & \ldots & u_{k}\end{array}\right]$.

Menurut kesamaan matriks, didapat $x=e_{1}+u_{1}+\cdots+u_{1 n}$. Jadi $l$ ideal bersih-n di $R$. $\square$

Proposisi 12. Diketahui ring $R$ dan $I$ ideal di $R . I$ ideal bersih-n di $R$ jika dan hanya jika terdapat himpunan elemen idempoten lengkap $e_{1}, e_{2}, \ldots, e_{k}$ sedemikian hingga $e_{i} l e_{i}$ ideal bersih-n dari $e_{i} R e_{i}$ untuk setiap $i=1,2, \ldots, k$.

Bukti. $\left(\Rightarrow\right.$ ) Terdapat $k=1$ dan $e_{i}=1$ sehingga $l$ ideal bersih $-n$ di $e_{i} R e_{i}={ }_{1} R_{1}=R$.

$(\Leftarrow)$ Cukup dibuktikan untuk $\mathrm{k}=2$. Diperhatikan bahwa $l \cong \mathrm{I}$ dan $R \cong \mathrm{R}$ dengan 


$$
\begin{gathered}
\mathrm{I}=\left\{\left[\begin{array}{ll}
e_{1} i e_{1} & e_{1} i e_{2} \\
e_{2} i e_{1} & e_{2} i e_{2}
\end{array}\right] \mid i \in I, e_{1}, e_{2} \in I^{\prime}(R), e_{1}+e_{2}=1\right\} \text { dan } \\
\mathrm{R}=\left\{\left[\begin{array}{ll}
e_{1} r e_{1} & e_{1} r e_{2} \\
e_{2} r e_{1} & e_{2} r e_{2}
\end{array}\right] \mid r \in I, e_{1}, e_{2} \in I_{1}(R), e_{1}+e_{2}=1\right\} .
\end{gathered}
$$

Diambil sebarang $A=\left[\begin{array}{ll}a_{1} & a_{1} \\ a_{2} & a_{2}\end{array}\right] \in \mathrm{R}$, didapat $a_{1}=e+u_{1}+\cdots+u_{n}$ dan $a_{2}=f+v_{1}+\cdots+v_{n}$ .Kemudian dibentuk $E=\left[\begin{array}{ll}e & 0 \\ 0 & f\end{array}\right]$ dan $U_{1}=\left[\begin{array}{cc}u_{1} & 0 \\ a_{2} & v_{1}\end{array}\right], \quad U_{2}=\left[\begin{array}{cc}u_{2} & a_{1} \\ 0 & v_{2}\end{array}\right], \quad U_{n}=\left[\begin{array}{cc}u_{n} & 0 \\ 0 & v_{n}\end{array}\right] . \quad$ Jadi didapat $A=E+U_{1}+\cdots+U_{n}$.

Karena $I$ isomorfis dengan $l$, didapat $l$ juga merupakan ideal bersih-n, untuk suatu bilangan asli $n$.

\section{Kesimpulan}

Dari pembahasan, dapat ditarik beberapa kesimpulan sebagai berikut:

1. Setiap ideal dari ring bersih $-n$ merupakan ideal bersih $-n$ dan ada ring tak bersih $-n$ yang memuat ideal bersih.

2. Jika $I$ ideal bersih maka $I$ merupakan ideal bersih- $n$ untuk setiap bilangan asli $n$. Namun jika untuk suatu bilangan asli $n, l$ merupakan ideal bersih $n$ maka $l$ belum tentu ideal bersih.

3. Jika setiap elemen idempotennya sentral, maka ideal peralihan merupakan ideal bersih- $n$. Namun ideal bersih $-n$ belum tentu ideal peralihan.

4. Ideal bersih- $n$ jika dikenakan epimorfisma maka petanya juga merupakan ideal bersih- $n$.

5. Pergandaan Kartesius dari ideal bersih $-n$ merupakan ideal bersih $-n$.

6. Jika $l$ ideal bersih- $n$, maka dapat dibentuk himpunan matriks atas sedemikian sehingga himpunan matriks tersebut merupakan ideal bersih- $n$.

7. Ideal bersih $-n$ mempunyai sifat yang mirip dengan ring bersih $-n$.

\section{Referensi}

[1] Adkins, W. A. 1992. Algebra "An Approach via Module Theory". Springer-Verlag, New York.

[2] Anderson, F.W. dan Fuller, K.R. 1992. Rings and Categories of Modules, Second Edition, Springer-Verlag, New York.

[3] Chen, H. dan Chen M. 2002. On Clean Ideals. Zhejian normal university. China.

[4] Fraleigh, J.B.. 1999. A First Course in Abstract Algebra, sixth edition. Wesley Longman, Inc. USA.

[5] Khaksari, A dan Moghimi, G. 2009. Some Results on Clean Rings and Modules, World Applied Sciences Journal ISSN 1818-3951. Iran

[6] Wang, Z. dan Chen, J.L. 2006. 2-Clean Rings*. arXiv:math/06109118v1. China. 